\title{
Identification of Novel and Recurrent RMRP Variants in a Series of Brazilian Patients with Cartilage-Hair Hypoplasia: McKusick Syndrome
}

\author{
Maria E. Gomes a Luiza Calatrava Paternostro ${ }^{a}$ Valéria R. Moura ${ }^{a}$ \\ Deborah Antunes $^{b}$ Ernesto R. Caffarena ${ }^{b}$ Dafne Horovitz ${ }^{c}$ \\ Maria T. Sanseverino ${ }^{d}$ Gabriela Ferraz Leale Têmis M. Felix ${ }^{f}$ \\ Denise Pontes Cavalcanti ${ }^{9}$ Juan Clinton Llerena Jr. c, h, i Sayonara Gonzalez ${ }^{a}$ \\ aLaboratório de Medicina Genômica, Centro de Genética Médica Dr. José Carlos Cabral de Almeida \& Centro de \\ Referência para Doenças Raras, IFF/FIOCRUZ, Rio de Janeiro, Brazil; 'baboratório de Biofísica Computacional e \\ Modelagem Molecular (PROCC), IOC/FIOCRUZ, Rio de Janeiro, Brazil; ' ${ }^{C}$ nnidade de Genética Clínica, Centro de \\ Genética Médica Dr. José Carlos Cabral de Almeida \& Centro de Referência para Doenças Raras, IFF/FIOCRUZ,

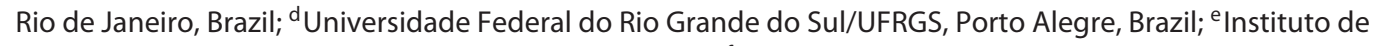

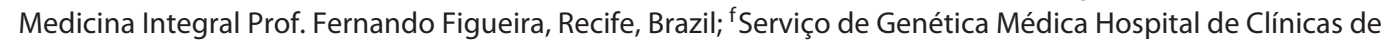 \\ Porto Alegre (HCPA), Porto Alegre, Brazil; ${ }^{9}$ Grupo de Displasias Esqueléticas, Departamento de Genética Médica, \\ FCM-UNICAMP, Campinas, Brazil; hINAGEMP - Instituto Nacional de Genética Médica Populacional, \\ Porto Alegre, Brazil; i Faculdade de Medicina Fundação Arthur Sá Earp Jr, Petrópolis, Brazil
}

\section{Keywords}

Cartilage-hair hypoplasia - Lymphoma - McKusick syndrome Metaphyseal bone dysplasia $\cdot R M R P \cdot$ RNase MRP

\begin{abstract}
Cartilage-hair hypoplasia syndrome $(\mathrm{CHH})$ is an autosomal recessive disorder caused by pathogenic variants of the $R M R P$ gene and characterized by metaphyseal bone dysplasia associated with hypotrichosis, immunodeficiency, and predisposition to malignancy. However, the genotype-phenotype correlation in $\mathrm{CHH}$ is not well understood. Here, we report a single country cohort of 23 Brazilian patients with clinical and radiological features consistent with $\mathrm{CHH}$. We found 23 different pathogenic variants in the RMRP gene - 12 novel and 11 previously described in the literature. Interestingly, the most frequent Finnish pathogenic variant related to $\mathrm{CHH}$ (g.71A $>$ G) was not found in our cohort. In contrast, more than
\end{abstract}

\section{KARGER}

(c) 2019 S. Karger AG, Basel

E-Mail karger@karger.com

www.karger.com/msy
$50 \%$ of the patients carried the rare g.196C $>$ T variant suggesting a possible founder effect in the Brazilian population. In silico analysis showed that pathogenic variants occurred either in the regions conserved in mammalian species or within essential domains for the ribonucleoprotein complex. Pathogenicity prediction studies can improve the understanding of how these variants affect RNA.

๑) 2019 S. Karger AG, Basel

Cartilage-hair hypoplasia syndrome $(\mathrm{CHH} ; 250250)$ is an autosomal recessive disorder with a broad clinical spectrum characterized by metaphyseal skeletal dysplasia, disproportionate short stature, joint laxity, light-colored fine and sparse hair, gastrointestinal problems, anemia, im-

J.C.L. and S.G. jointly supervised this work. 


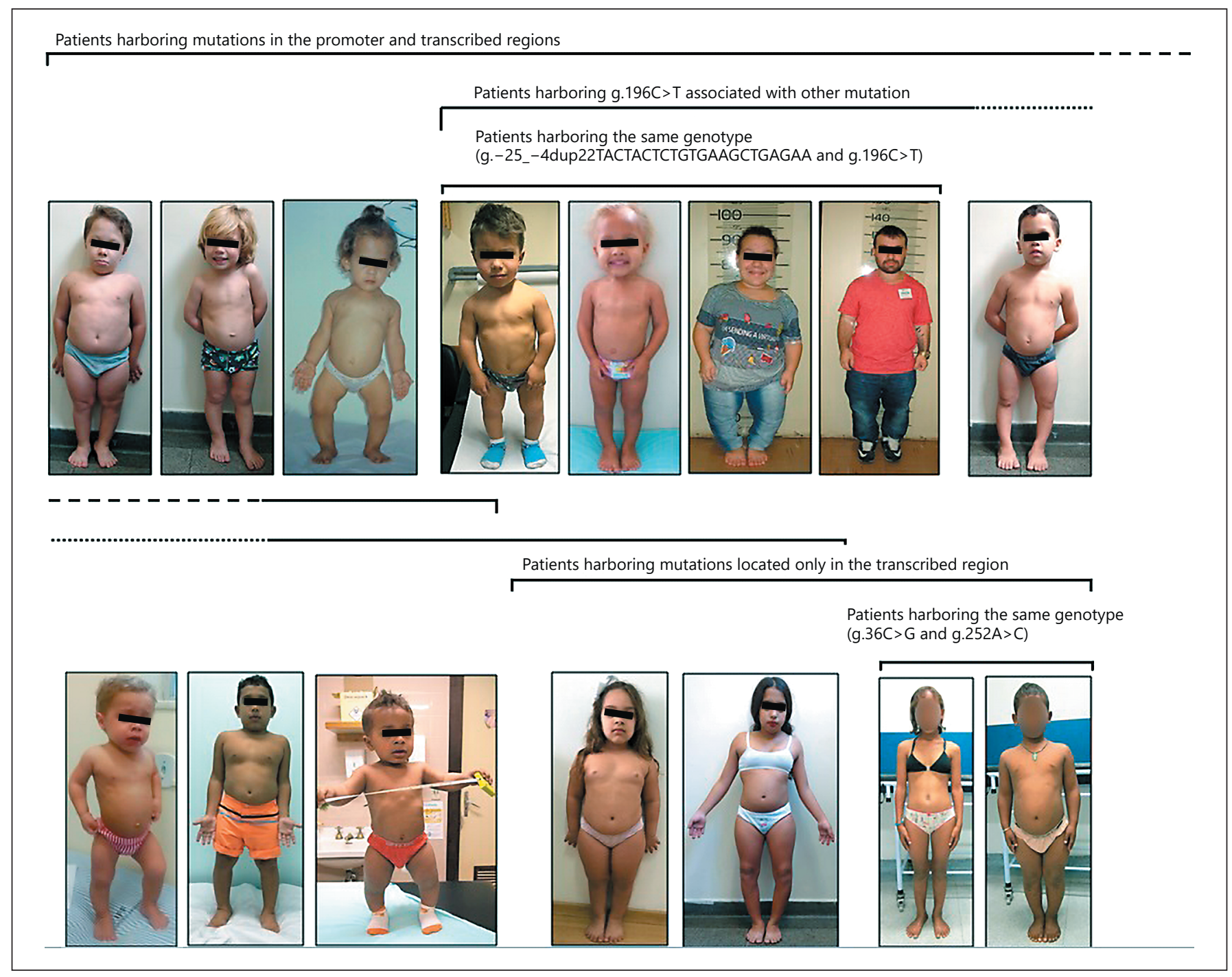

Fig. 1. Patients harboring variants in the $R M R P$ gene. Patients are presented according to their genotypes. Top, from left to right: patients $3,5,8,23,2,19^{+}, 20^{+}$, and 4 . Bottom, from left to right: patients $1,14,18,7,6,11^{*}$, and $12^{*}$. Superscripts indicate siblings.

munodeficiency, and increased susceptibility to cancer, such as lymphoma [Mäkitie and Vakkilainen, 2018]. Phenotypic variations have also been reported within individuals of the same family [Ridanpää et al., 2002].

$\mathrm{CHH}$ is associated with variants of the RMRP gene [Ridanpää et al., 2001]. This gene is located in chromosome 9p13 and encodes a 268-bp untranslated RNA that participates in the ribonuclease mitochondrial RNA processing (RNase MRP) complex involved in several ribonucleolytic cleavage events [Bonafé et al., 2002].

The most common variant in the $R M R P$ gene is g.71A $>\mathrm{G}$ found in $92 \%$ of the Finnish patients and in $48 \%$ of the non-Finnish CHH patients [Ridanpää et al., 2002].
A range of other pathogenic variants has also been reported: the resulting genotypes can occur as homozygous or as compound heterozygous combinations. Homozygous variants most frequently are located within the transcribed region, whereas compound heterozygous variants can be either in the promoter and in the transcribed regions or within the transcribed region only [Ridanpää et al., 2001; Bonafé et al., 2005]. Despite the wide spectrum of clinical presentations and a plethora of pathogenic variants described to date, the genotype-phenotype relationship in $\mathrm{CHH}$ is not well understood. Therefore, additional studies are required to better comprehend the mechanisms whereby those variants lead to the disease. 


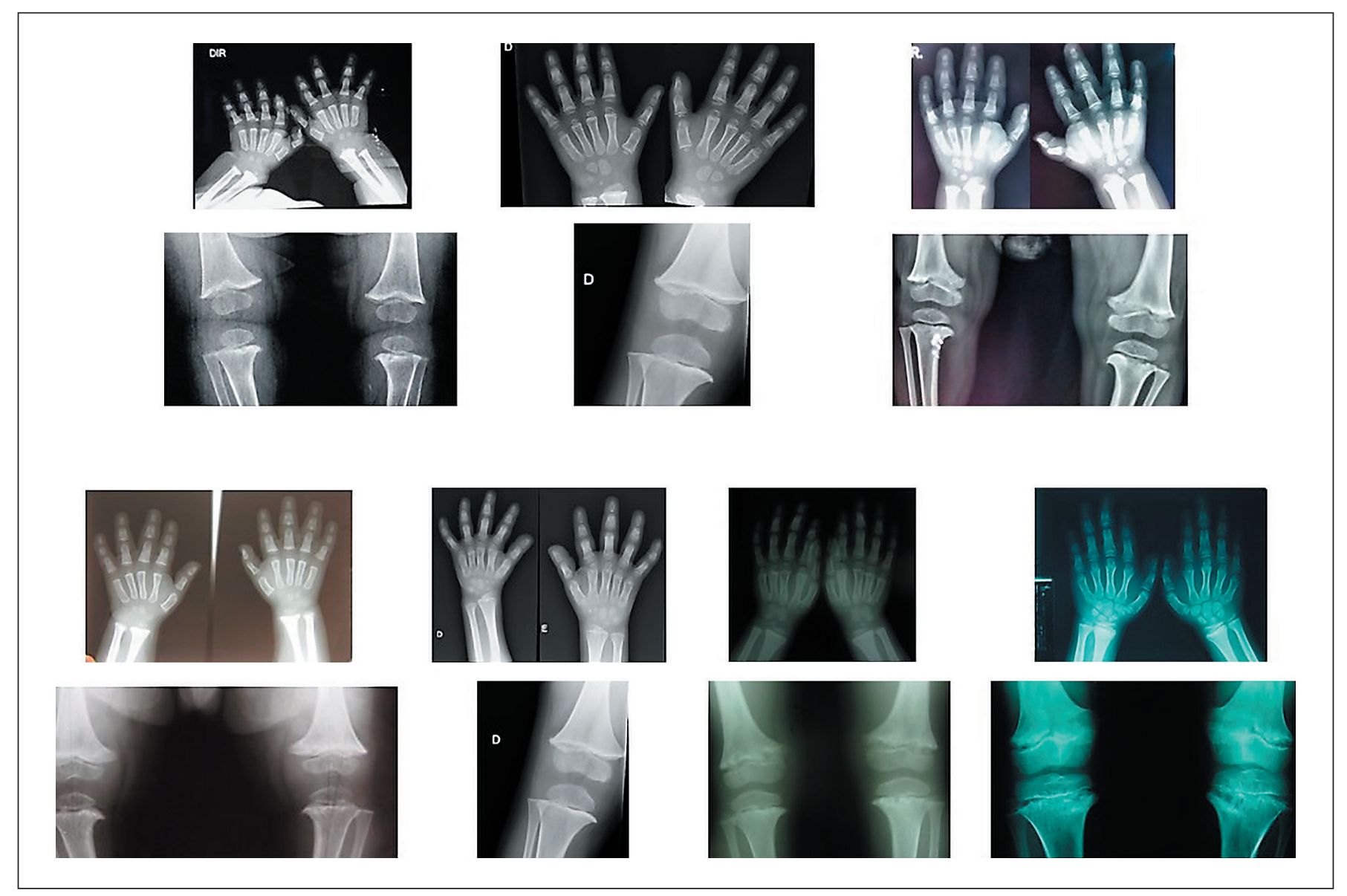

Fig. 2. Radiological changes in patients at different ages. Top row from left to right: patients 2,21 , and 4; second row, from left to right: patients $18,16,12$, and 8 . Besides brachydactyly, mainly at the expense of metacarpal shortening, metaphyseal cupping is seen in some proximal phalanges as well as cone-shaped phalangeal epiphyses with rounded half-moon shapes.

In this study, we describe recurrent and putative novel $R M R P$ variants in 23 Brazilian patients with clinical and radiographic characteristics of $\mathrm{CHH}$. We also performed structural analysis in order to predict potential pathogenicity of the variants identified in the transcribed region.

\section{Clinical Report}

We studied 23 Brazilian patients with a clinical-radiological diagnosis of $\mathrm{CHH}$ (10 females and 13 males). Patients' ages ranged from 4 to 25 years old. One female individual presented with hypotrichosis (patient 2), one patient was born from consanguineous parents (patient 21), and recurrence was observed in 2 families, each one with 2 affected siblings (patients 11/12 and 19/20). One patient died of non-Hodgkin lymphoma shortly after bone marrow transplantation at 10 years (patient 16) of age. Photos and radiological data from all patients are shown in Figures 1-3; clinical data were not assessed for several individuals due to loss of clinical follow-up. Although the immunological status for affected patients is a major issue and may lead to severe consequences, it was not investigated in the present work.

\section{Materials and Methods}

Three Brazilian medical centers participated in this study: Instituto Nacional de Saúde da Mulher, da Criança e do Adolescente Fernandes Figueira (IFF/Fiocruz - Rio de Janeiro; patients 1-7), Universidade Estadual de Campinas (UNICAMP - São Paulo; patients 8-15), and Hospital de Clínicas de Porto Alegre (HCPA Rio Grande do Sul; patients 16-23).

This study is a descriptive retrospective and prospective study with patients being recruited due to short stature, small hands and feet, and X-ray results compatible with a metaphyseal dysplasia. They were sent to IFF and HCPA, Reference Centers for rare diseases, as well as to UNICAMP, a specialized service in attending patients with congenital skeletal malformations and osteochondrodysplasia in Brazil. 
Fig. 3. Metaphyseal changes in the lower limbs in a patient at different ages. a At 9 months, in addition to shortened long bones, metaphyseal enlargement is evident in the knees. The tibiae are cupping and flaring in the distal metaphyses. b At the age of 5 years and 5 months, the same previous manifestations are observed and also some irregularities of the distal femoral metaphyses. The fibulae are longer than the tibia and coxa vara is present. c At the age of 10 years, metaphyseal irregularities of the knees as well as distal tibia metaphyses show some radiolucent areas. Some striations and coarse trabeculation of these areas are also evident. The fibulae shown are also longer than tibiae.

Table 1. $R M R P$ mutations found in the cohort of 23 Brazilian unrelated patients with cartilage-hair hypoplasia
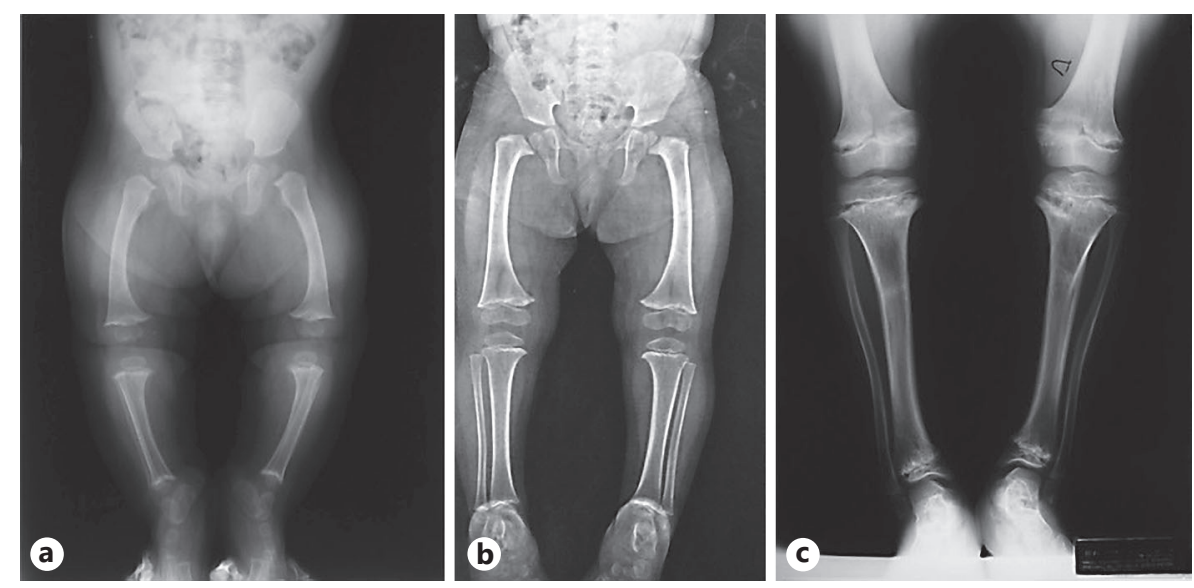

\begin{tabular}{|c|c|c|}
\hline $\begin{array}{l}\text { Patient } \\
\text { ID }\end{array}$ & Allele 1 & Allele 2 \\
\hline 1 & g.-21_-2dup20ACTCTGTGAAGCTGAGGACG & g. $196 \mathrm{C}>\mathrm{T}$ \\
\hline 2 & g. -25 _-4dup22TACTACTCTGTGAAGCTGAGAA & g. $196 \mathrm{C}>\mathrm{T}$ \\
\hline 3 & g.-19_-3trip17TCTGTGAAGCTGAGGAC & g. $194 \mathrm{G}>\mathrm{A}$ \\
\hline 4 & g.-22_-14dup9TACTCTGTG & g. $196 \mathrm{C}>\mathrm{T}$ \\
\hline 5 & g.-24_-15dup10ACTACTCTGT & g.97_98dup2(TG) \\
\hline 6 & g.97_98dup2TG & g. $196 \mathrm{C}>\mathrm{T}$ \\
\hline 7 & g.10T $>A$ & g. $196 \mathrm{C}>\mathrm{T}$ \\
\hline 8 & g.-19_-3dup17TCTGTGAAGCTGAGGAC & g. $181 \mathrm{G}>\mathrm{A}$ \\
\hline 9 & g. $6 \mathrm{G}>\mathrm{T}$ & g. $196 \mathrm{C}>\mathrm{T}$ \\
\hline 10 & g.-20_+3dup23CTCTGTGAAGCTGAGAACGTGGT & g. $5 \mathrm{C}>\mathrm{T}$ \\
\hline 11 & g.36C>G & g. $252 \mathrm{~A}>\mathrm{C}$ \\
\hline 12 & g. $36 \mathrm{C}>\mathrm{G}$ & g. $252 \mathrm{~A}>\mathrm{C}$ \\
\hline 13 & g.-13_+1dup14AAGCTGAGGACGTG & g. $196 \mathrm{C}>\mathrm{T}$ \\
\hline 14 & g.-8_-7ins20GGGACTACTCTGTGAAGCTG & g. $196 \mathrm{C}>\mathrm{T}$ \\
\hline 15 & g. -25 _-4dup22TACTACTCTGTGAAGCTGAGAA & g.97_98dup2(TG) \\
\hline 16 & g.97_98dup2TG & g. $147 \mathrm{G}>\mathrm{C}$ \\
\hline 17 & g. $6 \mathrm{G}>\mathrm{T}$ & g. $196 \mathrm{C}>\mathrm{T}$ \\
\hline 18 & $\begin{array}{l}\text { g. }-22 \text {-23dup20TACTCTGTGAAGCTGAGAAC } \\
\text { g.261_331dup70 }\end{array}$ & g.196C $>\mathrm{T}$ \\
\hline 19 & g. -25 -4dup22TACTACTCTGTGAAGCTGAGAA & g. $196 \mathrm{C}>\mathrm{T}$ \\
\hline 20 & g.-25_-4dup22TACTACTCTGTGAAGCTGAGAA & g.196C $>\mathrm{T}$ \\
\hline 21 & g. $36 \mathrm{C}>\mathrm{G}$ & g. $98 \mathrm{G}>\mathrm{A}$ \\
\hline 22 & g.69_70ins1T & g. $196 \mathrm{C}>\mathrm{T}$ \\
\hline 23 & g. -25 _-4dup22TACTACTCTGTGAAGCTGAGAA & g. $196 \mathrm{C}>\mathrm{T}$ \\
\hline
\end{tabular}

Recurrence was observed in 2 families, each one with 2 affected siblings (patients 11/12 and 19/20). 
Fig. 4. Representative electropherogram after allele discrimination of the RMRP gene of patient 1. a A duplication of a 9bp promoter fragment g.-22_-14dup9 TACTCTGTG combined with a point mutation (b) in the transcribed region (g.196C>T). c Alignment of the reference $R M R P$ sequence with the sequence of the allele that contains the 9-bp duplication in the promoter region (red rectangle). Blue rectangles mark polymorphisms.

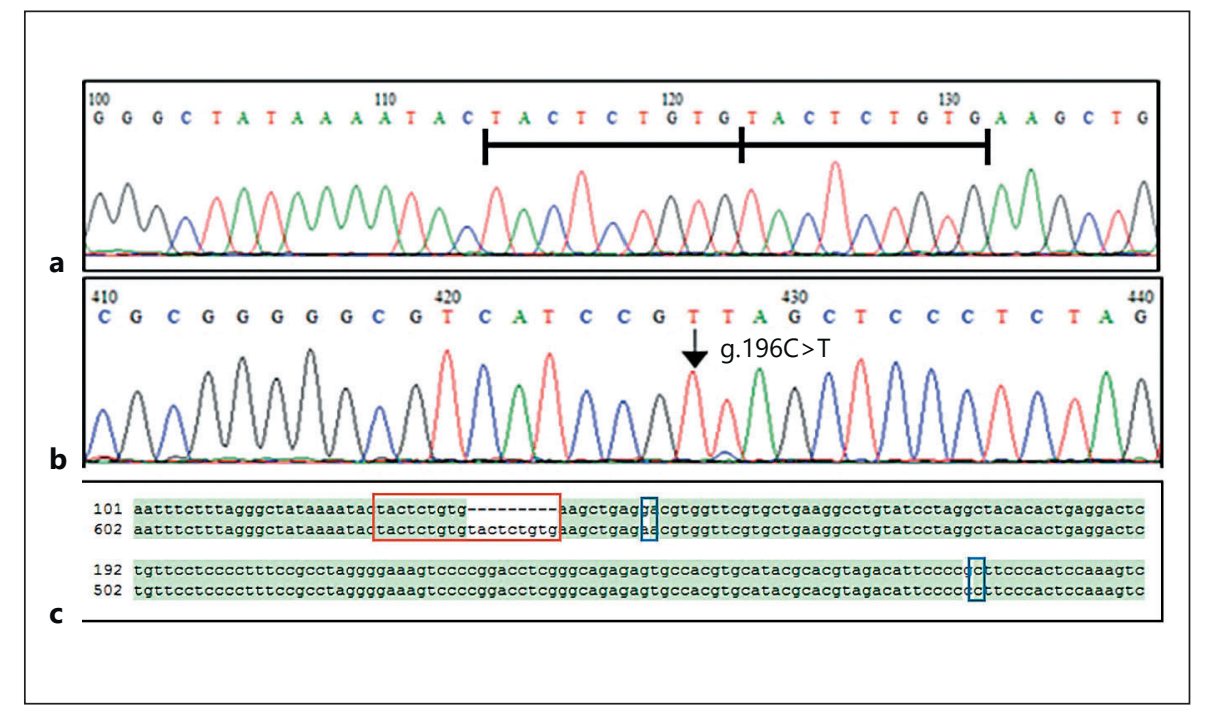

\section{Isolation of Genomic DNA}

Peripheral blood samples were collected from the patients with clinical and radiographic diagnosis of $\mathrm{CHH}$ using EDTA anticoagulant tubes. Genomic DNA was isolated by the salting-out method [Miller et al., 1988]. Genetic studies were also carried out, when available.

\section{DNA Amplification by PCR}

The whole promoter and transcribed regions of the RMRP gene were PCR-amplified using Eppendorf Mastercycler Gradient (Eppendorf, Hamburg, Germany) and purified by Wizard ${ }^{\circledR}$ SV Gel and a PCR Clean-Up System kit (Promega, Madison, WI, USA) according to the manufacturers' instruction. Primer sequences were kindly provided by Dr. L Bonafé (University Hospital in Lausanne, Switzerland; http://www.ncbi.nlm.nih.gov/Genbank/, accession number for the RMRP gene: M29916).

\section{Sanger Sequencing}

PCR products were directly sequenced for both strands by Sanger sequencing [Sanger et al., 1997] on an automated DNA sequencer ABI 3730 (Applied Biosystems, Foster City, CA, USA) using BigDye v3.1 Sequencing Buffer (Applied Biosystems) as described previously [Otto et al., 2008]. Sequence data were analyzed using BioEdit Software version 7.2 (Ibis Biosciences, Carlsbad, CA, USA). Variants were assigned based on the GRCh38 assembly. To confirm variants in individual alleles, the PCR fragments were cloned into TOPO TA Cloning (Promega), and several clones were sequenced.

\section{RNA Structure Mode}

The RMRP secondary structure was retrieved from the Rfam database (accession number RF00030) [Nawrocki et al., 2015] and compared to the published study on domain annotation [Walker and Avis, 2005]. The drawing and annotation were performed with Varna software [Darty et al., 2009]. Multiple sequence alignment was constructed using LocARNA (http://rna.informatik.unifreiburg.de/LocARNA/Input.jsp) [Smith et al., 2010]. LocARNA multiple alignments are shown in conjunction with the structure predicted by RNAalifold [Bernhart et al., 2008]. LocARNA computes pairwise alignments by dynamic programming using a progressive alignment strategy.

\section{Results}

\section{Detection of RMRP Variants}

Genotyping of the $R M R P$ gene was performed in 23 samples from patients with suspicion of $\mathrm{CHH}$. All patients were compound heterozygotes for the variants in the $R M R P$ gene (Table 1), and none of the patients with clinical suspicion of $\mathrm{CHH}$ were negative for $R M R P$ variants.

Fourteen patients presented with a combination of duplication, triplication, or insertion in the promoter region and a point mutation or small duplication in the transcribed region (Fig. 4). Genotypes of the other 9 patients comprised 2 distinct alterations in the transcribed region. In total, we detected 23 different variants, of which 12 were novel. None of the patients carried biallelic variants in the promoter region or the most common g.71A $>\mathrm{G}$ variant. Conversely, the g.196C $>\mathrm{T}$ variant was present in 14 out of 23 patients (60.9\%). In addition, concomitantly with pathogenic variants, we identified 7 known SNPs: g. $-57 \mathrm{~T}>\mathrm{C}$, g. $-55 \mathrm{~A}>\mathrm{G}$, g. $-47 \mathrm{C}>\mathrm{A}$, g. $-5 \mathrm{G}>\mathrm{A}$, g. $128 \mathrm{G}>\mathrm{C}$, g.157G $>C$, and g.178C $>$ T.

Notably, patient 18 presented with 3 variants: 2 of them, g.-22_-3dup20TACTCTGTGAAGCTGAGAAC and g.261_331dup70, in allele 1, and g.196C>T in allele 2. We also report 2 familial cases. In case 1, two siblings, a female and a male (patients 11 and 12, respectively) car- 


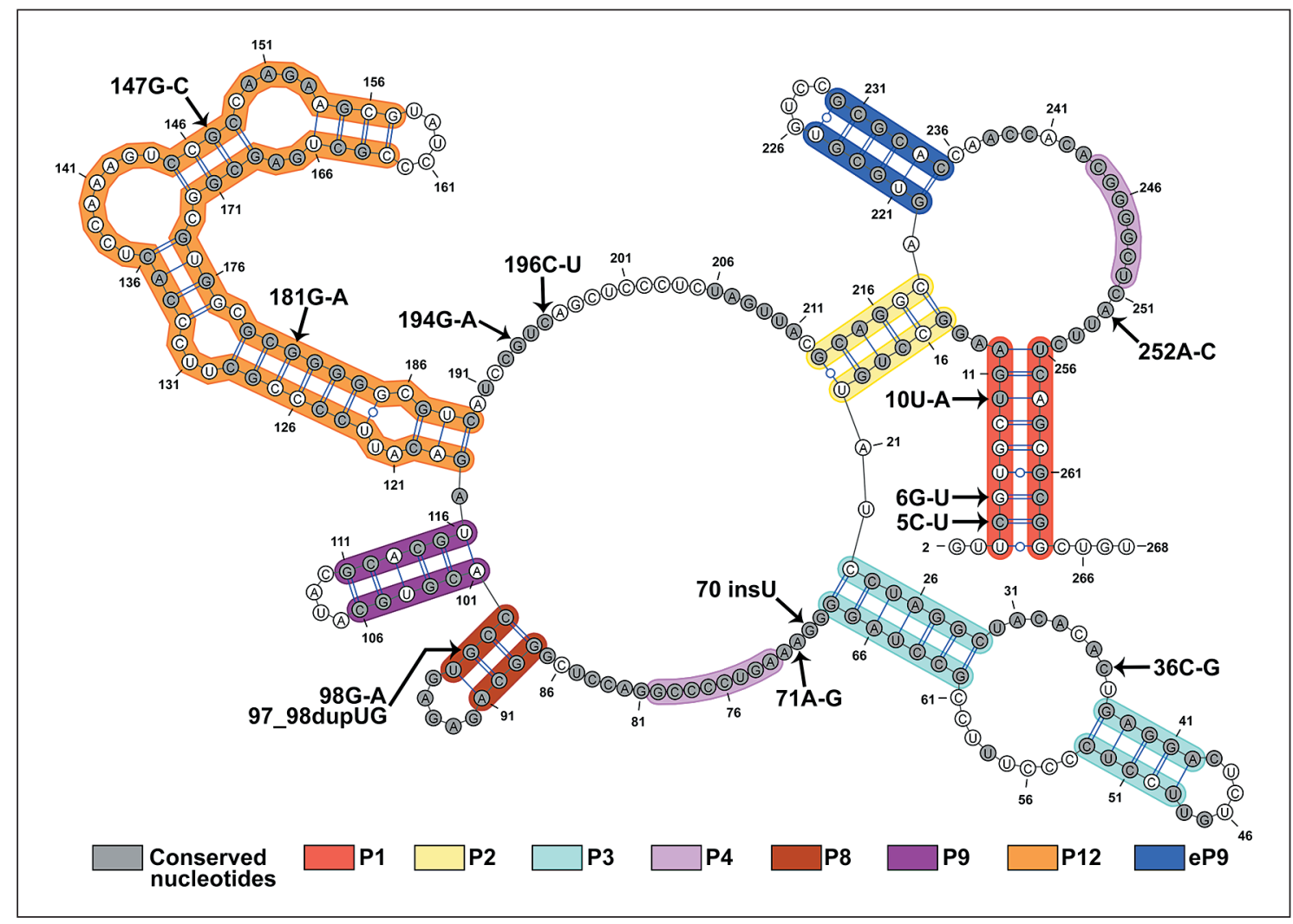

Fig. 5. Nucleotide variants in the secondary structure of RNase MRP. The annotation by domain of the structure is highlighted.

ried the g.36C $>\mathrm{G}$ and g. $252 \mathrm{~A}>\mathrm{C}$ variants. In case 2 , a brother and sister (patients 19 and 20), we found the genotype g.-25_-4dup22TACTACTCTGTGAAGCTGAGAA/g.196C > T. The last genotype was also found in 2 unrelated individuals (patients 2 and 23) (Fig. 1; Table 1). Surprisingly, patient 21 was born to consanguineous parents and showed 2 distinct variants (g.36C $>$ G/g. 98G $>$ A) (Table 1).

\section{Structural Analysis of RMRP Variants}

Thirteen variants were mapped on the secondary structure of wild-type human RMRP RNA. Among the identified variants, 7 were in the Watson-Crick base pairings: 5C $>\mathrm{U}, 6 \mathrm{G}>\mathrm{U}, 10 \mathrm{U}>\mathrm{A}, 98 \mathrm{G}>\mathrm{A}, 97$ 988dupUG, $147 \mathrm{G}>\mathrm{C}$, and $181 \mathrm{G}>\mathrm{A}$. Except for the variant $6 \mathrm{G}>\mathrm{U}$, all were located in conserved nucleotides. Also, the variant $36 \mathrm{C}>\mathrm{G}$ occurred in the sequence encoding the $\mathrm{P} 3$ domain (Fig. 5).

In this study, we utilized simulations of the plausible RNA folding to analyze the possible modifications in the RMRP domain regions. The variants $6 \mathrm{G}>\mathrm{U}$ and $10 \mathrm{U}>\mathrm{A}$
(Fig. 6a), 98G >A (Fig. 6c), 147G >C, and 181G >A (Fig. 6d) disrupt Watson-Crick base pairing, compromising the hairpin structure topology. Furthermore, the variant $5 \mathrm{C}>\mathrm{U}$, despite maintaining the pairing between nucleotides, produces a weaker interaction after losing $1 \mathrm{H}$ bond ( 3 bonds, $\mathrm{C}>\mathrm{G}$ vs. 2 bonds, $\mathrm{U}>\mathrm{G}$ ) (Fig. 6a).

Finally, the variants $36 \mathrm{C}>\mathrm{G}$ (Fig. 6b), 70insU, 71A $>\mathrm{G}$, $194 \mathrm{G}>\mathrm{A}, 196 \mathrm{C}>\mathrm{U}$, and $252 \mathrm{~A}>\mathrm{C}$ did not appear to modify the secondary structure, whereas the variant 97_98dupUG (Fig. 6c) increased the hairpin loop of the P8 domain. It is noteworthy that all these variants were located in the conserved regions.

\section{Discussion}

More than 100 different $R M R P$ variants have been associated with $\mathrm{CHH}$ [Mattijssen et al., 2010]. In our Brazilian cohort, the molecular analysis of 23 patients with $\mathrm{CHH}$ syndrome revealed 23 different variants in the $R M R P$ gene: 11 variants were previously described and 12 


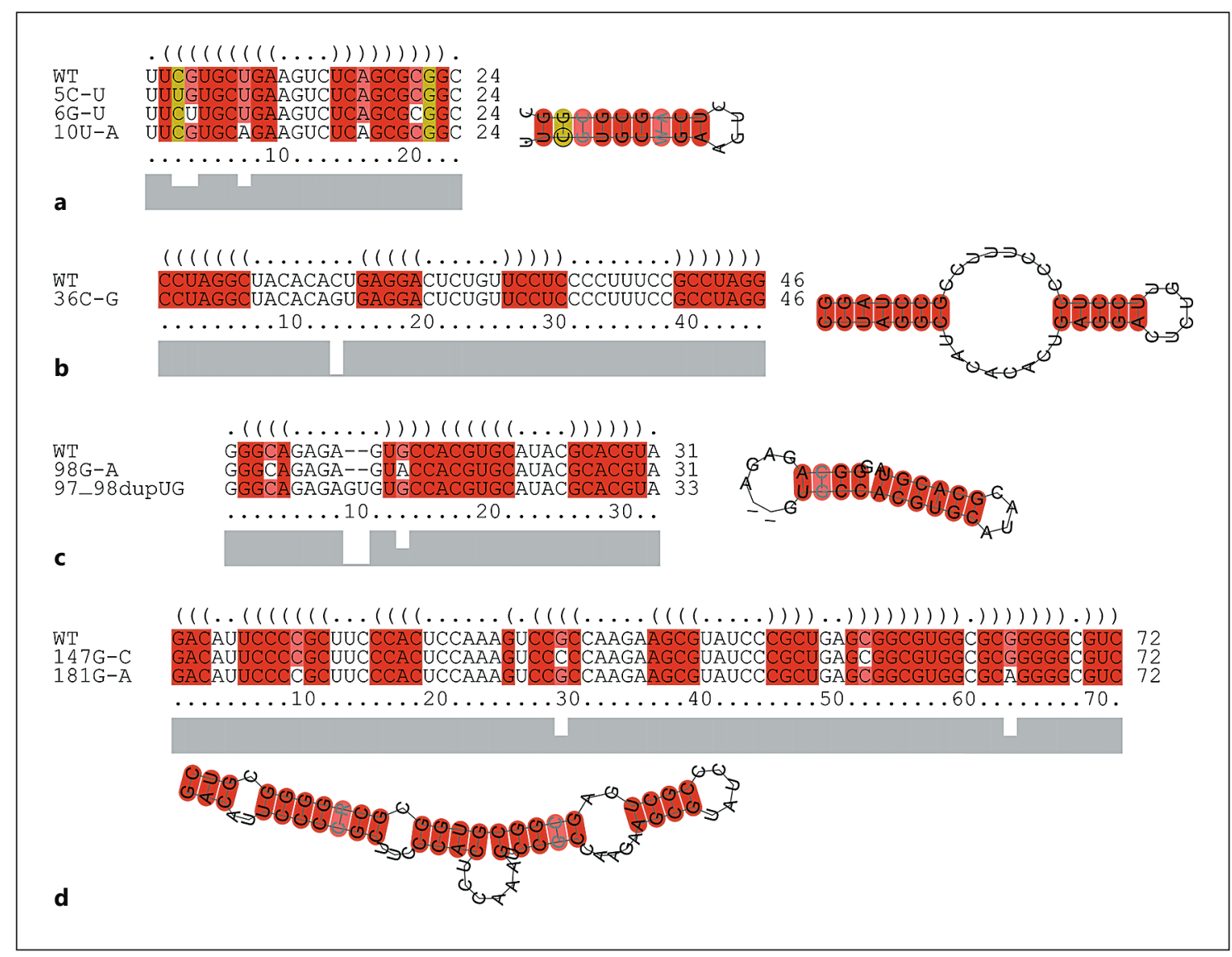

Fig. 6. Characterization of variants located in the RNase MRP complex domains. Alignment between the wild and mutant sequences is shown on the left. The secondary structure of alignment consensus is shown on the right. a Domain P1. b Domain P3. c Domain P8. d Domain P12.

were novel (Table 1). All genotypes showed compound heterozygosity. The pathogenic variants occurred concomitantly to polymorphisms already described in the literature [Bonafé et al., 2005]. In the present study, the prevalence of specific pathogenic variants was different from that observed in ethnically homogenous groups, such as Finnish or Japanese populations [Ridanpää et al., 2002; Hirose et al., 2006]. Indeed, we did not find the most frequent variant described in $\mathrm{CHH}$ patients so far (g.71 $\mathrm{A}>\mathrm{G})$ reported as a founder effect variant in the Finnish population and present in $48 \%$ of the other European $\mathrm{CHH}$ patients [Ridanpää et al., 2002]. Furthermore, a 17-bp duplication at position +4 and g.219A $>$ G, recurrent in Japanese population [Hirose et al., 2006], was also not detected in our cohort. However, in 14 out of 23 patients $(60.9 \%)$, we have found the previously described g.196C $>\mathrm{T}$ variant [Bonafé et al., 2005]. This mutation has been found in compound heterozygos- ity with g.-19_-13dupTCTGTGA, g.-15_-6dupTGAAGCTGAG, g.-19_-3dupTCTGTGAAGCTGAGGAC, g.65T>C, g.147G $>C$, g.221T $>C$, g.243A $>$ G, and g.255_264delCTCAGCGCGG [Ridanpää et al., 2002; Bonafé et al., 2005; Hermanns et al., 2006; Thiel et al., 2007]. It is noteworthy that we did not find the genotypes as mentioned earlier. Instead, g. 196C $>\mathrm{T}$ was observed in association with a large number of other variants (Table 1). The frequency of this variant was lower in gnomAD (MAF: 0.000008) and dbSNP (TOPMED-MAF: $0.0000008)$ databases, contrasting with our findings. It is worth mentioning that in gnomAD, the mutated allele g.196C $>$ T was present mostly in Latin American individuals. Additionally, the reported frequency of g. 196C $>\mathrm{T}$ in the literature is lower: $3 / 44(6.8 \%), 4 / 36(11.1 \%)$, and $1 / 27$ patients (3.7\%) [Ridanpää et al., 2002; Bonafé et al., 2005; Hermanns et al., 2006, Thiel et al., 2007]. These abovementioned findings, added to the fact that Brazilians 
should be considered a very mixed population [Moura et al., 2015], suggest that the g.196C $>$ T variant has a founder effect in the Brazilian population. However, further studies are needed to confirm this hypothesis.

Interestingly, one patient born to consanguineous parents (first cousins), showed 2 distinct variants (g.36C>G/ g.98G $>$ A). The frequency of both variants was investigated in several databases: in dbSNP (1000 Genomes), g.36C $>\mathrm{G}$ was found at a frequency of $\mathrm{C}=0.0002$, and in gnom $\mathrm{AD}$, instead of $\mathrm{C}>\mathrm{G}$, it was reported that c.36C $>\mathrm{T}$ was found at a frequency of 0.00006457.

Secondary structure analysis can be a way to infer the pathogenicity of newly identified $R M R P$ variants. Using computer simulations, we have characterized plausible consequences of possible modifications in the RMRP domain regions for RNA folding. Five variants $(6 \mathrm{G}>\mathrm{U}$, $10 \mathrm{U}>\mathrm{A}, 98 \mathrm{G}>\mathrm{A}, 147 \mathrm{G}>\mathrm{C}$, and $181 \mathrm{G}>\mathrm{A}$ ) were at the nucleotides involved in base pairing in the secondary structure of the RNA molecule, compromising the hairpin structure topology. Another variant $(\mathrm{C}>\mathrm{U})$ maintained the pairing between nucleotides but produced a weaker interaction after the loss of $1 \mathrm{H}$-bond $(\mathrm{C}>\mathrm{G}, 3$ bonds vs. $\mathrm{U}>\mathrm{G}, 2$ bonds), probably resulting in an unstable molecule and impaired complex assembly. Six variants, $36 \mathrm{C}>\mathrm{G}$, 70ins $\mathrm{U}, 71 \mathrm{~A}>\mathrm{G}, 194 \mathrm{G}>\mathrm{A}, 196 \mathrm{C}>\mathrm{U}$, and $252 \mathrm{~A}>\mathrm{C}$, did not affect the secondary structure. All mutations mentioned above, except for $6 \mathrm{G}>\mathrm{U}$, were located in an evolutionarily conserved region, suggesting their functional relevance [Bonafé et al., 2005]. Additionally, the variant $36 \mathrm{C}>\mathrm{G}$ occurred in the $\mathrm{P} 3$ domain, important for interactions between the RNA molecule and POP1, RPP20, RPP25, and POP4 proteins [Dávila et al., 2009]. Thus, P3 domain modification may compromise complex assembly. Our results also demonstrated that the 97_98dupUG variant increased the hairpin loop of the $\mathrm{P} 8$ domain, important for binding RPP20. Also, 147G $>C / 181 \mathrm{G}>\mathrm{A}$ variants occurred in the P12 domain, which is an important region for binding POP 1 and RPP38 to the RNA molecule [Welting et al., 2004].

Given the molecular variability of the RMRP gene mutation, the clinical phenotype in patients with $\mathrm{CHH}$ can be affected in several ways. The phenotype can also be influenced by the genetic background or epigenetic modifications which can modulate the penetrance of variants differently in patients with the same genotype. Indeed, differences in clinical and radiographic features have also been described in patients carrying a homozygous g.71A $>\mathrm{G}$ variant [Rider et al., 2009; Faitelson and Manson, 2015]. Despite not being able to provide genotypephenotype correlation due to missing clinical data in sev- eral patients, we still consider relevant to point out that only one patient of our cohort presented with an important hypotrichosis (patient 2), even though she shared the same genotype with 3 other patients (Fig. 1). In conclusion, 23 Brazilian patients have been clinically diagnosed with $\mathrm{CHH}$ and confirmed to have pathogenic variants within the RMRP gene. Furthermore, we described 12 novel variants in the $R M R P$ gene and suggested that the pathogenic variant g.196C $>\mathrm{T}$ was potentially a founder effect in the Brazilian population. The molecular results allowed genetic counseling of the families. In silico evaluation of the pathogenicity of $R M R P$ variants enabled to infer their effects on $R M R P$ RNA. This approach can be an important tool to assess the extent of the disruption of $R M R P$ function. Taken together, our observations broadened our knowledge regarding $\mathrm{CHH}$ syndrome and revealed the molecular profiles in Brazilian patients. These findings may contribute to a better understanding of $\mathrm{CHH}$ epidemiology in different patients around the world.

\section{Acknowledgments}

We are grateful to all physicians who provided us with patients' samples and data, and to the Plataforma Genômica - Sequenciamento de DNA - RPT01A (Rede de Plataformas Tecnológicas FIOCRUZ) which performed all Sanger sequencing. Finally, the authors wish to thank the patients and members of their families who participated in this study.

\section{Statement of Ethics}

This study was approved by the local Ethics Committee Board of each participating institution under the registrations 1.557 .698 and 1.339.799. Informed consent was obtained from all participants included in the study. All procedures performed in studies involving human participants were in accordance with the ethical standards of the institutional and/or national research committees and with the 1964 Helsinki Declaration and its later amendments or comparable ethical standards as per Brazilian 466/12 National Ethics Resolution.

\section{Disclosure Statement}

The authors have no conflicts of interest to declare. 


\section{Funding Sources}

This study was financed in part by the Coordenação de Aperfeiçoamento de Pessoal de Nível Superior, Brasil (CAPES), Finance Code 001 (grant to M.E.G.), the Programa de Estágio Curricular (PEC) IFF/FIOCRUZ (grant to L.C.P.), the Instituto Nacional de Saúde da Mulher, da Criança e do Adolescente Fernandes Figueira, IFF/FIOCRUZ and FAPESP 2015/22145-6 (grant to D.P.C.).

\section{Author Contributions}

Maria E. Gomes was responsible for patient genotyping, data curation, and manuscript writing. L. Calatrava Paternostro carried out allele discrimination by cloning. Valéria R. Moura was responsible for validation and allele discrimination by cloning. D. Antunes and Ernesto R. Caffarena were involved in the structural analysis of $R M R P$ variants. Maria T. Sanseverino, Gabriela Ferraz Leal, and Têmis M. Felix provided patient samples and data. D. Pontes Cavalcanti and J. Clinton Llerena Jr contributed to the design of the research, provided patient samples, and data. S. Gonzalez devised the project, data curation, and project administration. J. Clinton Llerena Jr. and S. Gonzalez also wrote the manuscript.

\section{References}

- Bernhart SH, Hofacker IL, Will S, Gruber AR, Stadler PF: RNAalifold: improved consensus structure prediction for RNA alignments. BMC Bioinformatics 9:474 (2008).

Bonafé L, Schmitt K, Eich G, Giedion A, SupertiFurga A: RMRP gene sequence analysis confirms a cartilage-hair hypoplasia variant with only skeletal manifestations and reveals a high density of single-nucleotide polymorphisms. Clin Genet 61:146-151 (2002).

Bonafé L, Dermitzakis ET, Unger S, Greenberg CR, Campos-Xavier BA, et al: Evolutionary comparison provides evidence for pathogenicity of $R M R P$ mutations. PLoS Genet 1:e47 (2005).

Darty K, Denise A, Ponty Y: VARNA: Interactive drawing and editing of the RNA secondary structure. Bioinformatics 25:1974-1975 (2009).

Dávila López M, Rosenblad MA, Samuelsson T: Conserved and variable domains of RNase MRP RNA. RNA Biol 6:208-220 (2009).

-Faitelson Y, Manson D: Cartilage-hair hypoplasia: a spectrum of clinical and radiological findings. LymphoSign J 2:157-164 (2015).

Hermanns P, Tran A, Munivez E, Carter S, Zabel $\mathrm{B}$, et al: $R M R P$ mutations in cartilage-hair hypoplasia. Am J Med Genet A 140:2121-2130 (2006).

Hirose Y, Nakashima E, Ohashi H, Mochizuki H, Bando Y, et al: Identification of novel RMRP mutations and specific founder haplotypes in Japanese patients with cartilage-hair hypoplasia. J Hum Genet 51:706-710 (2006).
Mäkitie O, Vakkilainen S S: Cartilage-hair hypoplasia - anauxetic dysplasia spectrum disorders, in Adam MP, Ardinger HH, Pagon RA, Wallace SE, Bean LJH, et al (eds): GeneReviews ${ }^{\circledR}$ [Internet] (University of Washington, Seattle 1993-2019). Initial posting: March 15, 2012; last update: May 24, 2018.

- Mattijssen S, Welting TJ, Pruijn GJ: RNase MRP and disease. Wiley Interdiscip Rev RNA 1: 102-116 (2010).

Miller SA, Dykes DD, Polesky HF: A simple salting out procedure for extracting DNA from human nucleated cells. Nucleic Acids Res 16: 1215 (1988).

Moura RR, Coelho AV, Balbino Vde Q, Crovella S, Brandão LA: Meta-analysis of Brazilian genetic admixture and comparison with other Latin America countries. Am J Hum Biol 27: 674-680 (2015).

Nawrocki EP, Burge SW, Bateman A, Daub J, Eberhardt RY, et al: Rfam 12.0: updates to the RNA families database. Nucleic Acids Res. 43(Database issue):D130-137 (2015).

Otto EA, Helou J, Allen SJ, O’Toole JF, Wise EL, et al: Mutation analysis in nephronophthisis using a combined approach of homozygosity mapping, CEL I endonuclease cleavage, and direct sequencing. Hum Mutat 29:418-426 (2008).

Ridanpää M, van Eenennaam H, Pelin K, Chadwick R, Johnson C, et al: Mutations in the RNA component of RNase MRP cause a pleiotropic human disease, cartilage-hair hypoplasia. Cell 104:195-203 (2001).
Ridanpää M, Sistonen P, Rockas S, Rimoin DL, Mäkitie O, Kaitila I: Worldwide mutation spectrum in cartilage-hair hypoplasia: ancient founder origin of the major $70 \mathrm{~A}>\mathrm{G}$ mutation of the untranslated RMRP. Eur J Hum Genet 10:439-447 (2002).

-Rider NL, Morton DH, Puffenberger E, Hendrickson CL, Robinson DL, Strauss KA: Immunologic and clinical features of 25 Amish patients with RMRP $70 \mathrm{~A}->\mathrm{G}$ cartilage hair hypoplasia. Clin Immunol 131:119-128 (2009).

Sanger F, Nicklen S, Coulson AR: DNA sequencing with chain-terminating inhibitors. Proc Natl Acad Sci USA 74:5463-5467 (1977).

-Smith C, Heyne S, Richter AS, Will S, Backofen R: Freiburg RNA Tools: a web server integrating IntaRNA, ExpaRNA and LocARNA. Nucleic Acids Res 38(Web Server issue):W373-W377 (2010).

Thiel CT, Mortier G, Kaitila I, Reis A, Rauch A: Type and level of RMRP functional impairment predicts phenotype in the cartilage hair hypoplasia-anauxetic dysplasia spectrum. Am J Hum Genet 81:519-529 (2007).

Walker SC, Avis JM: Secondary structure probing of the human RNase MRP RNA reveals the potential for MRP RNA subsets. Biochem Biophys Res Commun 335:314-321 (2005).

-Welting TJ, van Venrooij WJ, Pruijn GJ: Mutual interactions between subunits of the human RNase MRP ribonucleoprotein complex. Nucleic Acids Res 32:2138-2146 (2004).
Novel and Recurrent $R M R P$ Variants in Patients with McKusick Syndrome 